Article

\title{
Developing Inclusive Technical Capital beyond the Disabled Students' Allowance in England
}

\author{
Simon Hayhoe ${ }^{1,2, *}$, Kris Roger ${ }^{3}$, Sebastiaan Eldritch-Böersen ${ }^{4}$ and Linda Kelland ${ }^{4}$ \\ ${ }^{1}$ Centre for Philosophy of Natural and Social Science, London School of Economics, London, WC2A 2AE, UK; \\ E-Mail: S.Hayhoe@lse.ac.uk \\ ${ }^{2}$ Faculty of Education, Canterbury Christ Church University, Canterbury, CT1 1QU, UK \\ ${ }^{3}$ Centre for Learning Technology \& Innovation, London School of Economics, London, WC2A 2AE, UK; \\ E-Mail: K.Roger@Ise.ac.uk \\ ${ }^{4}$ Teaching \& Learning Centre, London School of Economics, London, WC2A 2AE, UK; \\ E-Mails: S.R.Eldritch-Boersen@Ise.ac.uk (S.E.-B.), L.Kelland@Ise.ac.uk (L.K.) \\ * Corresponding author
}

Submitted: 30 July 2015 | In Revised Form: 20 December 2015 | Accepted: 21 December 2015 |

Published: 28 December 2015

\begin{abstract}
The Disabled Students Allowance (DSA) is a government grant for students aged 18 years and over in English Higher Education. Amongst other things, this grant supports the provision of traditional assistive technologies. In April 2014, the UK's Minister for Universities, Science and Cities proposed cuts to the DSA. Although a later announcement delayed these cuts until the academic year 2016-2017, a number of universities are already preparing alternative means to support disabled students. In this article, it is argued that cuts to the DSA will potentially reduce the cultural and technical capitals of students with disabilities and lessen social inclusion in Higher Education. In particular, less support will potentially lead to a reduction in the development of study skills. As a counter weight, this article proposes a new model of inclusive technical capital. This model originates in Bourdieu's theory of cultural capital and habitus. The proposed model supports the use of native apps and settings in ubiquitous mainstream mobile technologies. It also espouses the use of m-learning for the passive inclusion of students with disabilities. This article also presents the early results of a project on the use of mobile technologies at the London School of Economics and Canterbury Christ Church University. This project found that students with disabilities and their lecturers already used mobile technologies alongside or instead of customized traditional assistive technologies. The project also found that students preferred not to attend, or found it difficult to attend, separate study skills courses using mobile technologies. However, they were more likely to access m-learning tutorial materials on Learning Management Systems. The study concludes that mobile technologies have the potential to develop a number of study skills that are at risk after cuts to the DSA. However, their use in this regard needs further research and support from universities.
\end{abstract}

\section{Keywords}

assistive technology; cultural capital; disability; exclusion; inclusion; inclusive technology; m-learning; mobile technical capital; smartphones; tablets; technology

\section{Issue}

This article is part of the special issue "Inclusive Technologies and Learning", edited by Don Passey (Department of Educational Research, Lancaster University, UK).

(C) 2015 by the authors; licensee Cogitatio (Lisbon, Portugal). This article is licensed under a Creative Commons Attribution 4.0 International License (CC BY). 


\section{Introduction}

This article examines the potential effects of the removal of the Disabled Students Allowance (DSA) by the United Kingdom government from students in Higher Education (HE) in England. It focuses on the possibility of the diminution of vital technical capital in disabled students, and the effects that this might have on the development of essential study skills. The article uses Yardi's (2010) model of technical capital-i.e. the skills in the use of and knowledge on modern technologies possessed by individuals - and its effects on exclusion. This is a techno-sociological adaptation of Bourdieu's (2010) model of cultural capital. That is it applies Bourdieu's original model designed to social and cultural knowledge to delineate social status to different levels of technological knowledge to delineate educational and social status. Yardi's model was chosen as it was designed to promote equality of opportunity through access to technical development through education, and other forms of knowledge and skill development.

To counter balance the possible effects of diminution of technical capital in disabled students, this article introduces a model of inclusive technical capital. This model develops the argument that knowledge of digital technologies can assist social inclusion of disabled people, as such knowledge can help their education and employment status. This model is based on the philosophy and use of assistive features and applications (apps) in contemporary mainstream technologies. In this context, it proposes the use of mobile smartphones and tablets by disabled students as tools to develop inclusive technical capital. Such technologies, it is argued, are also becoming ubiquitous for disabled students and non-disabled students in daily life worldwide. Therefore, it is argued that inclusive technical capital can potentially increase inclusion in other social and cultural spheres, as it increases social status and supports financial independence.

In order to test its hypothesis, this article continues by providing the findings of a pilot project. This project was designed to provide training and support for disabled students in two UK HE institutions: the London School of Economics and Political Science (LSE) and Canterbury Christ Church University (CCCU). This training was designed using an adapted version of grounded theory, termed grounded methodology (Hayhoe, 2012a). Although this model and the pilot project were based in English institutions, it is argued that their findings have international relevance. Many other developed countries have similar equality legislation to the UK, such as the Americans with Disabilities Act (ADA) which was introduced in 1990. Many other countries are also finding their funding squeezed, or have to provide support through private means. Thus, the model developed in this article is also designed to be used in parallel models of training in Higher Education settings other than the UK.
This article is necessary as the skills that are required to access information, data and knowledge through technologies are vital for providing social inclusion in mainstream culture. Technology can also provide tertiary skills, such as communication, literacy and access to social benefits. Thus, a lack of access to accessible technologies places disabled people at a disadvantage and less able to access education, training, benefits, support, social status and democratic representation. In addition, despite the increasing importance of ubiquitous mobile devices, little evaluation has been conducted on their use by disabled students (Hayhoe, 2013, 2015a, 2015b). This paper therefore defines a need for the investigation and evaluation of effective mobile technology use during class, lecture, seminar and individual study sessions. In doing so, it also assesses whether such technologies have an advantage over customised traditional accessible technologies, such as custom zoom devices and adapted keyboards.

This article is split into the following five sections. The first section defines the research methodology, data collection methods and the stages of analysis employed in the study. This section also defines some of the key terms used in the analysis of the data. The second section analyses the introduction and development of the DSA, and theorises possible problems that may occur when it is withdrawn. The third section develops the model of inclusive technical capital, and its implementation through the use of mobile technologies as tools of inclusion and access to education. This section also introduces a hypothesis about its implementation. The fourth section tests this hypothesis through the final stages of the evaluation of a study skills course at the LSE and CCCU, designed to support disabled students. The fifth section presents conclusions and recommendations for further research and the design of systems, pedagogy and support.

\section{Research Methodology and Data Collection}

\subsection{Methodology}

The methodology employed during this study was an adaptation of Grounded Theory (GT) (Glaser \& Strauss, 1967), termed Grounded Methodology (GM) (Hayhoe, 2012a). GM was previously developed to assess cultural inclusion of disabled students in mainstream and separate settings using the three coding phases of GT: Open Coding, Axial Coding and Selective Coding. Open Coding in GM is associated with identifying categories of behaviour, identity, objects or environments defined by the research. For example, in previous research on literature and the use of mobile technologies by disabled students learning environments were classified according to individual impairments (Hayhoe, 2013). Axial Coding in GM studies identify links between indi- 
vidual variables, such as gender, ethnicity or educational level, associated with the classifications identified in the Open Coding. At the end of the Axial Coding a hypothesis is made. During Selective Coding, evidence is gathered to test this hypothesis.

GM absorbed the technical elements of constantly comparing GT data and refined the methodology as an ongoing process of analysis, design and activity in the design of pedagogy. As with GT, in GM all discussions information, literature and theory were also regarded as data. Thus it was felt that this flexible approach to data collection and pedagogical design would suit the study of a potential pedagogical model. In the implementation of this previous model, it was also observed that the methodology allowed problem solving strategies to evolve in response to restricted resources.

Unlike GT, in previous iterations of GM hypotheses and theories were not induced. Furthermore, although GT is usually associated with purely qualitative studies, GM is more accommodating to mixed analyses of qualitative and quantitative data. The core of the methodology uses three phases of study, as with GT, through which data is analysed to a point at which a hypothesis can be formed and then selectively tested. The analysis is cyclical, as the selective testing of the hypothesis feeds into the initial stage of a further study if needed.

A further difference of GM and GT was its treatment of data collection as narratives developed by the researcher in order to state an original problem (Hayhoe, 2012a). Thus, Open Coding was analogous to identifying the problems to be narrated, and the identification of significant events effecting the research environment. Thus, initial data gathering for Open Coding can involve selecting a representative sample of subjects and their social contexts. Axial coding is analogous to the author developing their own plots of the narrative, and examining its evolution. It is also the development of a framework of analysis. At the end of the Axial Coding, a hypothesis is developed that will be tested in the Selective Coding. Finally, in a single cycle of research selective coding is analogous to choosing the meta-narratives that put the sub-plots together to form a complete narrative and test a hypothesis. Therefore, selective coding often involves reinvestigating a new sample or selectively sampling according to interactions with others subjects in order to test a hypothesis.

\subsection{Data Collection Methods}

In this study, Open and Axial coding phases consisted of literature searches, using a model developed by the lead investigation in a similar study (Hayhoe, 2013). The analysis of this literature is presented in the following two sections. The Open Coding focused on data related to the structure of and research on the DSA. It investigated the nature and problems encountered with the introduction of the DSA, and research related to up- take and the success of the DSA. The Axial Coding phase selected and developed a model of analysis of possible solutions. These used a social rather than a medical approach, as both CCCU and the LSE stated in their policies on support for disabled students, that they supported the social model of disability (CCCU, 2014; LSE, 2015).

The Selective Coding phase initially evaluated the assistive features of Apple's and Android's Operating Systems (OSs) and a number of free note taking apps (for comprehensive results of this evaluation, see Hayhoe, 2015b). These findings were taken into a survey of students at the LSE and CCCU self-identifying themselves as being disabled. This survey was supported by a quantitative and qualitative on-line survey of teaching staff at both institutions, using a Qualtrics survey platform - the quantitative questions elicited multiple choices, which were recorded on a Microsoft (MS) Excel spreadsheet. The questionnaire and the courses that followed were conducted in accordance with the British Educational Research Association's (BERA, 2004) guidelines on ethical research, and were passed by CCCU's Faculty of Education's Ethics Committee. These guidelines included providing full informed consent to the participants and promising full anonymity. It was also acknowledged that both the LSE and CCCU funded the project, and their students and staff provided the data. Therefore, there may have been a potential conflict of interest. The questions forming the surveys are listed in Table 1.

During this stage an initial survey of eighteen selfidentifying disabled students at the LSE and CCCU was conducted. These and a number of students were invited to participate in the survey through the relevant officers at the LSE and CCCU charged with supporting disabled students-exact numbers invited were not recorded, as the confidential relationship between support officers and the students invited was respected by those conducting the study. As this study was focussed on the DSA, only those students who would be potentially affected by the withdrawal of the grant were invited to participate. These students were identified by the learning support departments at both universities, as these departments were the first point of contact by disabled students. In addition, as this study focussed solely on the potential effects of the withdrawal of the DSA through the social model of disability, it was decided not to ask students about their specific disabilities or the strength of their disabilities. This point was emphasised recently by Oliver (2013), who emphasised disabled people should be evaluated according to their exclusion rather than the physical effects of their impairment.

Thirty four teaching staff who were aware of disabled students in their teaching groups at both universities were also surveyed. All teaching staff at both institutions were invited to participate in this study, via emails from departmental administrators and officers providing support to disabled students. In addition, the 
survey was also advertised through all-staff newsletters at the LSE and CCCU. Unfortunately, as with the students invited to participate few took up the invitation. As only few students and staff responded, the findings were not statistically significant, and so no detailed analysis was conducted on these data sets. However, their answers were consistent enough to produce guidelines for the development of support and course development, and had a supporting role in the analysis. Discussions were also conducted between key personnel at both universities. This included those working with neuro-diverse students (mostly those working with learning disabilities such as dyslexia and dyspraxia), physical and sensory disabilities and learning technologies.

Table 1. Questions posed to students and teachers participating in initial surveys at the LSE and CCCU.

Teacher Questionnaire
Q1 Are you aware of disabled students (such as visua
or neuro-diversity (such as dyslexia, dyspraxia or
dyscalculia) in your teaching groups? If yes, could you
please name the disabilities or neurodiversities.
Q2 Do disabled students use the following specialist
devices to access your materials or lectures: (a)
Brailers (b) Hearing aids (c) Magnification devices (d)
Hearing loops (e) None of these.

Q3 Do you find difficulties using specialist devices in your lectures/tutorials? If yes, please state briefly what problems you have encountered?

Q4 Do any of your disabled or neuro-diverse students use mobile devices, such as smart phones or tablets (e.g. iPhone, Samsung Galaxy, iPad, Kindle) in your class to, for example, record your lecture, or enlarge text?

Q5 Do your disabled or neuro-diverse students ask permission to use their smart phones or tablets during lectures or tutorials?

Q6 What do they record or read using their smart phone or tablet?

Q7 Do you prefer it if students DO NOT record your lectures/tutorials?

Q8 What materials are available to your students AFTER lectures?

Q9 What materials are available to your students BEFORE or DURING lectures?

Q10 If your students express a preference, do they prefer electronic or paper materials?

\section{Student Questionnaire}

Q1 Which of the following smartphones or tablets do you own-you may choose more than one: (a) iPhone (b) Samsung Galaxy Smartphone (e.g. S5/S5) (c) iPad (d) Android tablet (e) Windows tablet (f) Other (g) I do not own one.

Q2 Do you use your device to study or to help you in the following activities-you may choose more than one: (a) Taking notes by myself (b) Taking notes in lectures (c) Sound recording a lecture (d) Video recording a lecture (e) Accessing lecture notes (f) Seeing or zooming into a whiteboard or presentation (g) Seeing or zooming into far away writing or graphics (h) Accessing recorded lectures (i) Communicating with your lecturers or fellow students about work (j) Communicating with your lecturers or fellow students socially (k) Researching information on the web.

Q3 Have you used or do you use the following specialist devices-you may choose more than one: (a) Brailler (b) Hearing aid (c) Magnification device (d) Mobility device, such as wheelchair (e) None of the Above.

Q4 Do you tell your lecturer(s) that you use your device?

Q5 Are your lecturers/tutors aware of your specialist device?

Q6 If the same function of your specialist device was available through your tablet or mobile telephone, which would you prefer to use?

Q7 Do you find your specialist device helpful or unhelpful when studying or attending lecturesplease also briefly say how? 


\section{Open Coding-An Analysis of Literature on the DSA}

The Open Coding was initially focussed on the two questions: (1) What issues led to the initial introduction of the DSA? and (2) Could these issues be re-imposed given the withdrawal of the DSA? In an analysis of question 1, Riddell, Tinklin and Wilson (2004) discussed a significant expansion of UK HE from the mid-1980s onwards. This expansion also saw a growth in the number of disabled students attending universities, and therefore a growth in their potential development of cultural capital. However, the expansion of HE raised issues of access to facilities and support for disabled students, which had hitherto received little consideration.

In a survey of institutions' support of disabled students, Riddell (1998) observed that expansion often had a detrimental effect on students' well-being in this early era. This was the result of little consideration being given to the practical and social aspects of access to facilities by the management of universities, polytechnics and colleges. These problems were exacerbated from the start of expansion, as responsibility for support was devolved to universities, polytechnics and colleges by British government ministries. Consequently, little expertise existed in individual institutions.

Riddell also noted that disabled students were at greater risk of leaving their courses prematurely than their non-disabled counterparts in this early period of expansion. This was in part explicable as instructional technologies in this period were becoming increasingly pervasive in $\mathrm{HE}$, yet were based on traditional platforms (Reiser, 2001; Reiser \& Dempsey, 2011). These platforms were not designed with accessibility in mind and little thought was given to making their interfaces available through a range of media (Hayhoe, 2014b). Therefore it could be argued that this expansion posed a risk to the development and accumulation of technical capital by disabled students whilst at university, polytechnic or college.

After the election of a New Labour government in 1997, a number of initiatives were developed. These were designed to expand access to HE in the UK, and included the provision of support to those from low income households and under-represented social groups. These included disabled students (Riddell, Tinklin, \& Wilson, 2005). In 1999, the Higher Education Funding Councils (HEFC) for England also published a report addressing issues surrounding access for disabled students (HEFCE/HEFCW, 1999) -in Wales, England, Northern Ireland and Scotland HE was and is funded and administered separately. The report developed recommendations for providing support and retention, and provided more coherent, homogeneous national standards of access.

In a later study of HE in England and Scotland, Riddell et al. (2004) found that institutions were increasingly developing policies to support disabled students (in the context of this study see, for example, CCCU, 2014; LSE, 2015). These policies included policies for providing access to the built environment and teaching-despite this more coherent approach, however, a gap was observed between policy and practice. In particular, many HE institutions made access the sole responsibility of relatively small support services rather than attempting to initiate whole institutional changes. Riddell et al. (2004) also observed that students found it difficult to accept a disabled identity or admit their disability at university, as they felt this would affect their intellectual identity. This made it difficult to identify their needs and provide support services. Furthermore, Riddell et al. (2004) observed that disabled students often found it difficult to socialise with and integrate themselves into the cultural life of their peers. This led to further pressures on students' wellbeing and social inclusion.

Viney (2009) observed that it was within this social and cultural environment that the DSA was first introduced into UK HE institutions in the early 1990s. This introduction came under the stewardship of the then Conservative government, during the early period of HE expansion. The DSA was and is a government grant for students who are normally resident in UK and in $\mathrm{HE}$, and was administered by the various student finance agencies in the UK.

The DSA was designed only for students who studied on taught courses that were equivalent to degrees, or on courses that fed into degrees-undergraduate and postgraduate, vocational and academic. Its specification also included vocational undergraduate courses that were considered to be lower than normal honours degrees-such as Higher National Certificate/Diplomas and certain forms of General National Vocational Qualification. This provision also included foundation degreestwo year degrees which did not include an honours element-as well as full bachelors and taught postgraduate degrees. In order to claim the DSA, students have to fulfil the legal definition of disability, which is currently defined by the 2010 Equalities Act thus:

You're disabled under the Equality Act 2010 if you have a physical or mental impairment that has a 'substantial' and 'long-term' negative effect on your ability to do normal daily activities.... What 'substantial' and 'long-term' mean: 'Substantial' is more than minor or trivial e.g. it takes much longer than it usually would to complete a daily task like getting dressed. 'Long-term' means 12 months or more e.g. a breathing condition that develops as a result of a lung infection. (HM Government, 2014)

The DSA was designed only to provide non-medical support. It was particularly intended to finance the following four categories of support for disabled students (Stevens, 2013): 
Specialist equipment allowance. This category was for the purchase of specialist equipment or software that was above and beyond what a nondisabled student would need to conduct their studies. This could include specialist assistive technologies, such as Brailers or specialist software, if these had not been provided previously. However, for certain forms of disability where students' impairments were better served by mainstream technologies, DSAs could be used to buy a laptop or PCalthough this was only where the student could not normally afford a computer or had a low specification devise. This feature of the DSA was designed to support writing and research for writing.

Non-medical helper's allowance. This category paid for the employment of non-medical, educational support specialists. Outside of educational institutions, specialists were provided by health or social security agencies. Examples of specialists allowed under the DSA were sign language interpreters to support deaf students, and note takers and specialist tutors for students with dyslexia and dyspraxia. This category also included specialists who provided mobility support for those who used wheelchairs.

Travel costs. This category covered the expenditure of bus and taxi fares of students who had physical difficulties travelling to and from their institutions by what was considered to be normal means. This expenditure included the cost of specialist taxi or bus services for students who used wheelchairs or crutches, or who had forms of palsy.

General and other expenditure allowance. This category included incidental expenditure that was not included in the other three categories. Examples of this expenditure included photocopying notes for students with learning difficulties, and the photocopying enlargement of materials for students with low vision.

In relation to an analysis of question 2, a report by the UK's National Audit Office (2007) observed that disabled students as a whole obtained greater success on degree courses if they received the DSA. In particular, it was found that retention figures were significantly higher for students receiving the grant. Similarly, a report by the National Association of Disability Professionals (NADP) also observed that a significant increase in the number of $\mathrm{HE}$ disabled students was at least in part due to the uptake of the DSA (Viney, 2009). Furthermore, it was found that the introduction of the DSA also led to an increase in students declaring previously hidden disabilities - numbers of students declaring learning difficulties, mental health issues and mul- tiple disabilities had especially increased since the introduction of the grant. However, it was unknown whether this increase was due to a genuine rise in numbers, more diagnoses or the increase in those who were willing to admit to having a disability-i.e. whether there was a cultural shift in understanding disabilities due to a criticism of the deficit model of disability.

However, other studies suggested that the ability to attain resources is premised largely on factors unrelated to students' disabilities. Research also suggested that the DSA was not always successful in targeting students who arguably needed it most. For example, Tinklin, Riddell and Wilson (2004) discovered that many disabled students were still reluctant to declare their disabilities. Often it was felt that for students to identify themselves as such would not fit their cultural persona-although it was observed that students were more likely to declare certain forms of what were felt to be more socially acceptable disabilities, such as dyslexia. Tinklin et al. (2004) also observed that because students had to apply for the DSA at the beginning of their courses, they were disadvantaged in this essential transitional period.

A later study by the same authors suggested that there was an improvement in the management of access in HE after the election of New Labour in 1997 (Riddell et al., 2005). However, despite initiatives to provide more equitable access, students who benefitted most were male, middle class and dyslexic-social class was largely felt to influence their decision to declare their disability. Therefore, they benefitted most from the DSA. Riddell (1998) also criticised the previous liberal management of support for disabled students. She found that it was often based on the individual good will of academic staff and managers, without substantial resourcing from the institutions themselves.

Given this analysis of the two questions that were the focus of Open Coding, the manner in which the proposal to reduce the DSA was analysed in order to identify the timeframe of a potential solution to its withdrawal. On the 7th April 2014, the UK's Minister for Universities, Science and Cities proposed cuts to the DSA, starting in the academic year beginning September 2015 (Clark, 2014). After this period, student welfare would again be the responsibility of individual universities and colleges, who were also legally liable for continued inclusion. This decision received significant criticism from the national Students Union (Morgan, 2014). They argued that cuts to the grant were against current thinking on inclusion in $\mathrm{HE}$.

After a change of minister and representations from university management and student groups, the original decision to repeal the DSA was postponed for a further 12 months. This move was designed to provide universities and colleges with extra time to prepare their responses to the changes and design inclusive practices. 
In a ministerial statement of the $12^{\text {th }}$ September 2014, the then new minister of state, Clarke, made the following statement in mitigation of his decision:

I am determined to ensure that a university education is open to everyone who can benefit, including disabled people. Where disabled students need support, they will have it-whether from universities discharging their statutory duty or through the Disabled Students' Allowances, which I have decided to retain [for 2015-2016]. (Clarke, 2014, p. 2)

In analysis of the Open Coding as a whole, it was observed that the DSA had some impact where students self-identified as being disabled, and where resources were provided as a result of the DSA. Thus it was decided that the Axial Coding should identify a solution based on social inclusion over physical or learning impairment, again in accordance with the social model of disability. In addition, it was felt that support should focus on socially accessible and inclusive technological solutions for overcoming the withdrawal of technologies purchased with the DSA. This potentially gave rise to a model of inclusion that would allow a greater number of students than those currently claiming the DSA, who were largely middle class. The following section discusses the resulting model of inclusive technical capital in part response to the proposed cuts to the DSA. This model was based on a theory of inclusion based on class and technology, that of Cultural Capital (Bourdieu, 2010). The resulting model proposes that existing and increasingly ubiquitous mobile technologies may at least play a part in counteracting any subsequent, potential exclusion.

\section{Axial Coding-An Analysis of Technical Capital}

The Axial Coding was focused on a question, What social model can lead to greater social and cultural inclusion in $H E$, and possibly negate increased financial and physical capital? It was decided to found this model on Bourdieu's model of social and cultural capital as a foundation, as for Bourdieu (2010) capital was multifarious and not just financial. Beyond traditional Marxist approaches to capital accumulation (Marx, 2011), Bourdieu argued that it was not just material wealth that caused division between humans. For Bourdieu, accumulation also included social and cultural capitals, such as access to education, artistic tastes, accent and language. These comprised a complex yet subtle societal distinction. For Bourdieu, a person could be financially poor, but if he or she had accepted tastes and pronunciation they could be regarded as having high social and cultural status.

Bourdieu (1990) also ascertained that social and cultural capitals were acquired through agencies such as the family, peer groups and institutions more than financial capital. Moreover, unlike financial capital and material accumulation, social and cultural capitals were unlikely to change or be lost during life course. They were therefore more secure capitals for those that possessed them. Bourdieu described the process of accumulating these intangible capitals as the internalisation of subconscious habits. He named this concept habitus and defined it as the "principles which generate and organise practices." (Bourdieu, 1990, p. 53)

In the context of health analysis and psychological learning behaviour, habitus has been defined as being internalized traditions that lead to cultural practices (Lizardo, 2004; Swartz, 2002). Habitus can thus be regarded as deep seated, internalized structures of cognitive understanding beyond more formal systems of language-i.e. it is our unspoken codes. This approach seems particularly relevant to an analysis of inclusion in the education of disabled students. As habitus precedes the learning objectives of formal education (Swartz, 2002), lacking habitus of basic study skillssuch as note taking, developing graphics, structuring writing and conducting web searches-can potentially exclude students from educational success. For example, Hayhoe's (2014a) case studies on blind people's use of the Internet to search for art works observed that lack of success led to negative social identity. This in turn led them to believe that they could not or had little capacity to learn through this medium. Similarly, cultural capital also comprises the accumulation of conscious knowledge on the prevailing culture. This includes knowledge on the use of and access to prevailing technologies (Bourdieu, 2010).

The habitus of study skills can also lead to the development of cultural capital in other aspects of education too. This can be said to reinforce this habitus in more traditional forms of learning and develop the social identity of a student as one who can learn (Hayhoe, 2014a). This process thus becomes cyclical. For example, knowledge on the use of technology can be defined as cultural capital. For students who are visually impaired or dyslexic, for example, technology may allow them to develop the habitus of accessing audio format books. This in turn can make a visually impaired or dyslexic student develop cultural capital, such as knowledge from the contents of the book. This process becomes a recurring practice, and allows the student to develop the identity of a knowledgeable and successful student. This fulfilment continues to develop technical capital in order to reinforce a habituated social identity, and the principles of learning.

Bourdieu's discussion on different forms of capital has been criticised by theorists for being too rigid, deterministic, and lacking social evolution (Alexander, 1995; Chaney, 1996). Furthermore, Lamont (1992) argued that Bourdieu's general observations were too subjective and full of generalisations. Similarly, Fowler (1999) noted that many writers found his views par- 
ticularly Franco-centric. He also argued that Bourdieu overlooked the irony of members of the middle class aping the habitus of the working classes by, for example, erroneously deriding high culture. However, Seale, Georgeson, Mamas and Swain (2015) and Seale (2013) find that forms of capital can often support social inclusion through education in technological skills-often referred to as digital capital. Bourdieu (2010) argued that it was through such forms of education that the practice of studying individual fields of education can become part of the viewer's social identity. This academic social identity was subsequently referred to as a field of study or knowledge, which resulted in further development of habitus and cultural capital. This in turn demonstrated the practice of a person applying their cultural capital within a given epistemological field. Bourdieu formulated this process in the generation of action or practice as follows:

\section{$[($ habitus $)($ capital) $]+$ field $=$ practice (Bourdieu, 2010, p. 95)}

Taking inspiration from Bourdieu's theory of cultural capital, Yardi defines technical capital as: "the availability of technical resources in a network, and the mobilization of these resources in ways that can positively impact access to information and upward mobility." (Yardi, 2010, p. 1). Technical capital is thus used as an instrument to analyse social network interactions, and the ability of people to function and develop cultural inclusion. This use of capital also increases the potential development of further capitals, such as social and financial capitals. This is due to the ability to work online, allowing users to access certain forms of education, apply for certain types of employment and talk with people who may further their social status. For example, Brock, Kvasny and Hales (2010) found that the use of on-line social forums designed specifically for black women enabled its users to culturally empower themselves. This form of communication, they argued, would have otherwise been unavailable to them without technical capital.

This analysis led to two questions: (1) Can the DSA increase the technical capital of disabled students? and (2) If it can, what could possibly happen when the DSA is removed? In relation to question 1 , inclusive technical capital was redefined in the analysis in relation to both Yardi's (2010) model of technical capital and Bourdieu's (2010) notion of cultural capital and habitus. It was defined as, practice using inclusive mainstream technologies to promote inclusion in forms of social, cultural and financial capitals through enabled habitus in education and training (Hayhoe, 2015a). A further outcome of inclusive technical capital was that it attempted to find alternatives to custom built traditional assistive technologies. In the context of inclusive technical capital, assistive technologies are defined ac- cording to Seale's broad definition of assistive technology that encompasses e-learning:

[Assistive technology is] a subset of e-learning and specifically defined as any tool that supports and enables disabled learners to engage in the learning process and complete the learning tasks associated with this process. (Seale, 2014, p. 8)

Hayhoe (2014b, 2015b) argues that customised traditional assistive technologies, such as hearing aids and separate electronic magnifiers, do not promote inclusion for three primary reasons. Firstly, it is argued that they identify and draw attention to disabled students in educational environments. Secondly, it is found that they socially and culturally separate and exclude people with disabilities from those who are able bodied in other mainstream environments. This separation is similar to the mechanism by which students were sent to isolated environments up until the latter decades of the Twentieth Century (Hayhoe, in press). Thirdly, it is argued that some customised traditional assistive technologies, such as Braillers or technologies related to mobility, provide reasons not to include disabled students in mainstream education. This is due to the highly specialised nature of the skills needed to use these technologies and to train disabled students. For example, it is argued that this separation necessitates students' removal from lessons in order to provide separate training (Hayhoe, 2014b).

It can be argued that inclusive technical capital is applicable to students' use of new forms of mainstream settings and apps that have been embedded in modern tablet devices. Therefore, these devices lend themselves to redefinition as inclusive technologiesi.e. mainstream technologies that can be used by people with disabilities with little or no adaptation (Hayhoe, 2014b). These devices are powerful tools of social inclusion, have inclusive applications in educational settings, and are often used by students to create and share information (Hayhoe, 2013).

In relation to question 2 , modern accessible digital technologies have helped to make literature, communication and knowledge available to disabled students (Baga, 2012; Chen, 2012; Gkatzidou \& Pearson, 2009). In addition, software has overcome barriers to education through, for example, the audio description of books, re-colouring of text on screen, and representation of sound as text (Hayhoe, 2012b, 2014b). However, Hayhoe (2014b) also argues that such technologies have seen a paradigm shift, inevitably leading to a contemporary philosophy of inclusive technology. This has transformed systems' design to focus on accessible systems that are virtually indistinguishable from their mainstream counterparts. Examples cited of this technology are Apple's iOS, which claims superior accessible features blended into mainstream apps and func- 
tions (Apple, 2015) and Google's Android OS.

This led the Axial Coding to develop a hypothesis based on two social issues. The first issue was that of reducing a need for traditional assistive technologies and the need for large amounts of financial capital. The reason for this decision was that traditional assistive technologies were not only expensive and thus financially prohibitive. This potentially decreased exclusion based on socio-economic class. Secondly, it was decided to develop a hypothesis based on the cost effective development of study skills used at the LSE and CCCU, based on existing resources and personnel. This potentially increased cultural capital through skills that were easily accessible to HE students as a whole. Eventually, the hypothesis formed for the selective coding phase of the project was:

Students would find a course developing general study skills useful. A model based on three primary study skills-note taking, recording of lectures and mind mapping-currently used in these universities using technologies that many of them already own would be most useful. Students would also want to learn these skills by attending discrete study skills sessions once every two weeks, during lunch time, in order to lessen their need to make their disabilities known to non-disabled students. In addition, students would want to access materials online to support their sessions.

\section{Selective Coding-The Development of a Course to Support Self-Identifying Disabled Students}

The Selective Coding began with an initial analysis of apps and accessibility settings in the two most popular mobile operating systems, Apple's iOS and Google's Android OS-as stated previously a detailed analysis of this section of the study has been published in detail elsewhere (Hayhoe, 2015b). This evaluation observed that mobile technologies' accessible functions and apps were generally separated according to media and gestures. This was not apparently an issue with regards to the development of traditional technical capital and study skills.

Furthermore, as devices did not necessarily reveal the true identity of the user, they also allowed students to keep their disability anonymous and develop a socially and culturally ambiguous identity. These skills would thus allow the user to create, manage and swap information in a number of different formats with people of similar educational backgrounds. However, this could only occur if knowledge of their use was available. Therefore, it was thought that mobile technologies were potentially more useful as tools to establish inclusive technical capital if support was also provided. This appeared to support the notion that study skills should be based on sound recordings, visual enhancement and the physical access to mobile devices. It was felt that this reframing of traditional skills socially excluded disabled students with a number of strengths and types of disabilities. Thus, using these devices would be in compliance with the social model of disability, and thus the policies of CCCU and the LSE.

For example, iOS and Android allowed for text enlargement, colour reversal and saving and changing video files in order to increase their quality. It was therefore concluded that they had the potential to include disabled students in mainstream HE settings, where recording and researching didactic information was necessary. However, these observations were also unbalanced as a number of settings and functions in different devices varied significantly. It was felt that the quality and function of the technology in particular could also affect inclusion. For example, Android's native facilities allowed for audio recording, and organizing and sharing audio files whereas iOS's did not. Similarly, iOS had native apps that allowed for photonegative images, time-lapse recordings and custom gestures. These functions were not available in Android. Therefore, it was concluded that specialists with knowledge of both systems could help attend to the most efficient usage.

The survey of staff showed that a strong engagement with disabled students and their customised traditional assistive technologies were needed. For example, 23 out of 34 teaching staff knew that they taught disabled students. Similarly, 19 of 34 teaching staff also stated that they had no problem using customised traditional assistive technologies, with only 6 expressing difficulties. Of the majority of traditional assistive devices seen by staff, 27 of the 34 were related to hearing impairments, and 7 teaching staff were related to visual impairments.

The staff survey also demonstrated that there was a noticeable shift by disabled students to the use of mobile technologies in order to develop study skills. For example, 31 staff members stated that disabled students used mobile devices. In this group, 26 teaching staff found that students asked permission at least some of the time to use these devices. There was also a positive response to this use, with 24 of teaching staff not objecting to recordings by students during lectures-although an additional 8 teaching staff stated that it depended on context.

The survey's results also indicated that there was a balance between disabled students using mobile devices to access existing materials and those to create their own notes. In particular, where disabled students used mobile devices in lectures and seminars 8 of 34 teaching staff stated that they were recording their own notes. Students participating in the course also appeared to be emphatic in their preference for mobile devices. In the initial survey, all students stated that they used mobile devices, with 8 disabled students us- 
ing iOS devices, 5 using Android, 2 using Windows and 4 using other systems. Similarly, when asked if a function were available through a mobile device and through a customised traditional assistive device which would they prefer to use, all students stated that they would prefer using the mobile device. On the implementation of their own mobile devices, students most often used them to access, research and communicate information and materials from lectures. Recording was the least significant use of these technologies.

It was felt that the initial survey showed that the students and staff who responded preferred to use mobile technologies as inclusive devices. Similarly, conversations between stakeholders at the LSE and CCCU suggested that students would like a course based on study skills involving mobile technologies. It was also felt that students would prefer discrete sessions on specific study topics as a means of support. The discourse of staff in the meetings suggested that the most useful study skills were: accessing mobile settings, note taking, mind mapping and recording information.

The implementation of the course design was in two parts. The first part was a number of sessions run at the LSE and CCCU from October 2014 to January 2015. The second part of this phase was the uploading of teaching materials, tutorials and videos of the sessions on the LSE's Learning Management System (LMS)although only LSE students could access this material. This was based on a Moodle platform. The third part of this phase was an evaluation by the students of the course, a measure of students' attendance and downloads on the LMS. Unfortunately, only 3 students participated in the evaluation-all were from the LSE. Therefore, their findings were insignificant and eventually not counted in the measurement of the hypothesis.

The observations of the course and the statistics that were recorded provided a relatively clear picture of preferences. At the LSE, 24 students registered on the LMS. Of these students, all but 2 accessed the ma- terials independently. Materials were also accessed after the course and evaluation had finished. An example page of these statistics is shown in Figure 1. Conversely, attendance of classes was small and fluctuated at both institutions. During the note-taking, 10 students attended at the LSE and 5 students attended at CCCU. During the mind-mapping session, 6 took part at CCCU but only 1 attended at the LSE-although this could partially be explained by the emphasis on the use of mind-mapping in the extensive use of coursework at CCCU. Finally, during the video and sound recording session, 2 students attended at the LSE and 4 attended at CCCU.

Discourse from the students recorded during and after the sessions suggested that they did not attend at the LSE and CCCU for different reasons. At CCCU, where students had lower entry requirements and were more likely to be of British origin, students were happier to admit their disabilities - most students had dyslexia. Their stated reasons for not attending all sessions were that they clashed with lectures and that sessions were in a different location from their normal teaching campus. Conversely, students at the LSE, who were more likely to have higher entry requirements and to be international students, were less likely to discuss their disabilities. Of those that did, most again had dyslexia. One student at the LSE fed-back that she felt that separate sessions were patronising to her as a disabled student.

There was evidence to suggest that disabled students at the LSE preferred to access materials via an LMS rather than attend a separate course for students with similar educational needs. Statistics on access to the LSE's LMS also appeared to show a more varied image of preferences for training when they could access the training material independently. The most hit link was that on note-taking apps. In all three session pages, video recordings (Echo-360 recordings) of sessions were also on average more popular than the MS PowerPoint tutorials.

\section{Note-taking and Sharing Information}

\begin{tabular}{|c|c|c|c|}
\hline - Note-taking Session Recording (Echo 360 link) & 7 & - & Monday, 2 February 2015, 4:47 PM (140 days 4 hours) \\
\hline 굼 Notetaking Apps Roundup & 42 & - & Tuesday, 3 February 2015, 9:24 AM (139 days 11 hours) \\
\hline Share your Apps here! & 23 & - & Monday, 26 January 2015, 9:20 PM (146 days 23 hours) \\
\hline - Additional resources & 7 & - & Monday, 2 February 2015, 4:49 PM (140 days 4 hours) \\
\hline - Scrivener web site & 11 & - & Monday, 26 January 2015, 9:23 PM (146 days 23 hours) \\
\hline Eduroam Guides & 8 & - & Monday, 10 November 2014, 12:26 PM (224 days 8 hours) \\
\hline Tutorials on Note Taking & 9 & - & Monday, 2 February 2015, 4:47 PM (140 days 4 hours) \\
\hline Tutorials on Accessible Settings & 4 & - & Monday, 26 January 2015, 9:23 PM (146 days 23 hours) \\
\hline
\end{tabular}

Figure 1. Example breakdown of statistics showing downloads of note taking materials. 
The findings from the selective coding phase did not support certain elements of the hypothesisalthough it should be emphasised that the numbers participating in the survey and the courses were so small that findings were not wholly reliable. Students did not attend the separate face-to-face sessions in large numbers, suggesting that their preference was not for separate support. This meant that there was little impact on the disabled student body's use of technology passed on through such support, and little impact on inclusive technical capital. Nevertheless, there was greater access of materials on the LMS, and downloads of the tutorials that were offered. These were also accessed at different times and in greater numbers. Furthermore, only 2 students did not access materials. Thus, it can be suggested that more anonymous sources of support and information are more likely to develop inclusive technical capital in future iterations of this project.

\section{Conclusion}

Technical capital is applicable to disabled students. Students with physical impairments and learning disabilities can find it difficult to access knowledge, but technologies can assist in reversing this problem. The proposed changes to the UK's DSA will undoubtedly threaten the development of technical capital, as it will reduce disabled students' access to technologies that assist study skills-for example, recording lectures to replay and study independently. Consequently, HE institutions are currently in a precarious position as providers of support for disabled students, and need to develop a coherent strategy. The development of inclusive technical capital for disabled students is also important in the development of social, cultural and financial capitals. Thus, cuts to the DSA may have consequences beyond $\mathrm{HE}$.

One possible technical solution to cuts to the DSA is the use of ubiquitous technologies, particularly those that are increasingly used by disabled students. Mobile devices have come a long way in helping reduce technical exclusion, as their price has reduced significantly in recent years, and their interfaces are relatively easy to use. Furthermore, their developers are making significant progress in making popular mobile systems inclusive learning devices for disabled students. In addition, it has been found that new uses of existing apps and improvements to interface quality can provide significant improvements to accessibility.

The project reported in this article has made an attempt to co-ordinate an approach and theory of inclusion beyond customised traditional assistive technologies. Although the findings are not conclusive, largely because of the small sample involved, some findings provide pointers for future research, development for support and social inclusion. In particular, it would seem that students in this project preferred using mainstream mobile devices over traditional separate assistive technologies given the choice to do so. However, in common with students in previous studies of $\mathrm{HE}$, disabled students were occasionally reluctant to identify themselves as having impairments. It was also difficult to time sessions to allow all to attend, therefore flexibility seemed necessary. This makes providing support for disabled students particularly challenging in HE. This would at least in part explain why students at the LSE were happier to join and access the LMS relatively anonymously rather than attend face-to-face sessions.

However, this model of inclusive technical capital needs further evaluation as a tool of design and support. For example, for practice to be enhanced, the environment of learning and habits/habitus that are developed at university need further identification. This would make its approach more sophisticated and identify individual students' needs. It also needs to develop a broad, culturally diverse body of theory in order to provide a co-ordinated response to the social exclusion of disabled students. Findings from the early evaluation of settings and literature in the open coding found that modern mobile devices can help in the useful development of inclusive technical capital. However, disabled students and those that support them must evaluate systems according to individual impairments and educational needs. They must also judge which functions are important given their personal context and environments.

Consequently, the most popular mobile operating systems still need to develop their functions in cooperation with all educational institutions and disabled students. Developers also need to standardise mainstream native apps and hardware for people with disabilities. In short, there needs to be an increasingly universal approach to design and inclusion. Furthermore, larger manufacturers need to make their mobile devices more affordable in order to evaluate their potential as tools of inclusion and cultural diversity. Only then will inclusive technical capital be attainable by the masses, and social inclusion become truly meritocratic.

\section{Acknowledgements}

We would like to acknowledge the LSE's Centre for Learning Technology and Innovation and CCCU's Faculty of Education for providing grants for this project.

\section{Conflict of Interests}

The authors declare no conflict of interests.

\section{References}

Alexander, J. C. (1995). Fin de siècle social theory: Rela- 
tivism, reduction and the problem of reason. New York: Verso.

Apple. (2015). Accessibility. Retrieved from https:// www.apple.com/uk/accessibility/ios

Baga, J. (2012): E-resource round up: Emerging technology as assistive technology: Conference report. Journal of Electronic Resources Librarianship, 24(1), 4648.

BERA. (2004). Revised ethical guidelines for ethical research. Southwell, Nottinghamshire: British Educational Research Association.

Bourdieu, P. (1990). The logic of practice. Stanford, CA: Stanford University Press.

Bourdieu, P. (2010). Distinction. London: Routledge Classics.

Brock, A., Kvasny, L., \& Hales, K. (2010). Cultural appropriations of technical capital: Black women, weblogs, and the digital divide. Information, Communication \& Society, 13(7), 1040-1059.

CCCU. (2014). Equality and diversity policy statement. Canterbury: Canterbury Christ Church University. Chaney, D. (1996). Lifestyles. London: Routledge.

Chen, L. L. (2012). Integrating iPad in a special education class: A case study. In T. Bastiaens \& G. Marks (Eds.), Proceedings from the World Conference on ELearning in Corporate, Government, Healthcare and Higher Education 2012. Chesapeake, VA: AACE.

Clark, G. (2014). Written ministerial statement by Rt. Hon Greg Clark, Minister of State for Universities, Science and Cities on the 12th September 2014: Student support. London: Department for Business, Innovation and Skills.

Fowler, B. (1999). The sociology of habit: The perspective of Pierre Bourdieu. Variant, 2(8), 1-4.

Gkatzidou, S., \& Pearson, E. (2009). The potential for adaptable accessible learning objects: A case study in accessible vodcasting. Australasian Journal of Educational Technology, 25(2), 292-307.

Glaser, B. G., \& Strauss, A. L. (1967). The discovery of grounded theory: Strategies for qualitative research. Chicago, IL: Aldine Publishing Company.

Hayhoe, S. (2012a). Grounded theory and disability studies: Researching legacies of blindness. Amherst, New York: Cambria Press.

Hayhoe, S. (2012b). Using an iPad with a blind student: A case study at Sharjah Women's College. In S. Dowling, C. Gunn, H. Donaghue, J. Raven, \& S. Hayhoe (Eds.), elearning in action (Vol. 1): Opening up learning. Abu Dhabi: HCT Press.

Hayhoe, S. (2013). A review of the literature on the use of mobile tablet computing as inclusive devises for students with disabilities. In Proceedings of the Current Trends in Information Technology 2013 Conference, Dubai, December 2013. New Jersey: IEEE.

Hayhoe, S. (2014a). An enquiry into passive and active exclusion from sensory aesthetics in museums and on the Web: Two case studies of final year students at California School for the Blind studying art works through galleries and on the web. British Journal of Visual Impairment, 32(1), 44-58.

Hayhoe, S. (2014b). The need for inclusive accessible technologies for students with disabilities and learning difficulties. In L. Burke (Ed.), Research, reflections \& arguments on teaching \& learning in a digital age. Melton, Suffolk: John Catt Publishing.

Hayhoe, S. (2015a). Utilising mobile technologies for students with disabilities. In A. Robertson \& R. JonesParry (Eds.), Commonwealth education partnerships-2015 (Vol. 16). Cambridge: Commonwealth Secretariat \& Nexus Strategic Partnerships.

Hayhoe, S. (2015b). A pedagogical evaluation of accessible settings in Google's Android and Apple's iOS mobile operating systems and native apps using the SAMR model of educational technology and an educational model of technical capital. In Proceedings of INTED2015 9th International Technology, Education and Development conference, March 2015. Valencia: IATED.

Hayhoe, S. (in press). The epistemological model of disability, and its role in understanding passive exclusion in Eighteenth \& Nineteenth Century Protestant educational asylums. International Journal of Christianity and Education, 20(1).

HEFCE/HEFCW. (1999). Guidance on base-level provision for disabled students in Higher Education institutions. Bristol: HEFCE.

HM Government. (2014). Definition of disability under the Equality Act 2010. Retrieved from http://www. legislation.gov.uk/ukpga/2010/15/section/6

Lamont, M. (1992). Money, morals and manners: The culture of French and American upper-middle class. Chicago: Chicago University Press.

Lizardo, O. (2004). The cognitive origins of Bourdieu's habitus. Journal for the Theory of Social Behaviour, 34(4), 375-401.

LSE. (2015). School's policy on disability. London: London School of Economics.

Marx, K. (2011). Capital: A critique of political economy. Mineola, NY: Dover Publishing.

Morgan, J. (2014). Disabled Students' Allowance cuts postponed. Retrieved from https://www.timeshigher education.co.uk/news/disabled-students-allowancecuts-postponed/2015720.article

National Audit Office. (2007). National Audit Office value for money report: Staying the course, the retention of students in Higher Education. London: HMSO.

Oliver, M. (2013). The social model: A victim of criticism. Disability Now. Retrieved from http://www.disability now.org.uk/article/social-model-victim-criticism

Reiser, R. A. (2001). A history of instructional design and technology: A history of instructional media (Part 1). Educational Technology Research and Development, 49(1), 53-64.

Reiser, R. A., \& Dempsey, J. V. (2011). Trends and issues 
in instructional design and technology. London: Pearson.

Riddel, S. (1998). Chipping away at the mountain: Disabled students experience of Higher Education. International Studies in Sociology of Education, 8(2), 203222.

Riddell, S., Tinklin, T., \& Wilson, A. (2004). Disabled students and multiple policy innovations in Higher Education: Final report to ESRC. Edinburgh: Centre for Educational Sociology, University of Edinburgh.

Riddell, S., Tinklin, T., \& Wilson, A. (2005). New Labour, social justice and disabled students in Higher Education. British Educational Research Journal, 31(5), 623-643.

Seale, J. (2013). When digital capital is not enough: reconsidering the digital lives of disabled university students. Learning, Media and Technology, 38(3), 256-269.

Seale, J. (2014). E-learning and disability in Higher Education. New York: Routledge.

Seale, J., Georgeson, J., Mamas, C. \& Swain, J. (2015). Not the right kind of 'digital capital'? An examination of the complex relationship between disabled students, their technologies and Higher Education institutions. Computers \& Education, 82, 118-128.

Stevens, T. (2013). Applying for Disabled Students' Allowances (DSAs): Disability rights $U$ factsheet F1. Retrieved from http://www.disabilityrightsuk.org/print $/ 241$

Swartz, D. L. (2002). The sociology of habit: The perspective of Pierre Bourdieu. The Occupational Therapy Journal of Research, 22, 615-695.

Tinklin, T., Riddell, S., \& Wilson, A. (2004). Disabled students in Higher Education, briefing 32. Edinburgh: Centre for Educational Sociology, Edinburgh University.

Viney, D. (2009). Report on Disabled Students Allowances: Situation from the National Association of Disability Practitioners. Warwick, Warwickshire: NADP.

Yardi, S. (2010). A Theory of technical capital. Paper delivered to the TMSP Workshop, Georgia Institute of Technology, Georgia, US, February 11-12, 2010. Retrieved from http://tmsp.umd.edu/position\%20pa pers/Yardi-SocialMediatingTech.pdf

\section{About the Authors}

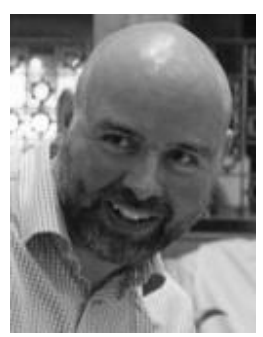

\section{Dr. Simon Hayhoe}

Simon Hayhoe is Program Director for the MA Special Needs and Inclusion and Coordinator of the Special Educational Needs section of the Ed.D at Canterbury Christ Church University. He is also a Centre Research Associate in the Centre for the Philosophy of Natural and Social Science, LSE. In addition, Simon is one of the theme group leaders for the Inclusion, Equalities and Social Justice Research Theme Group in the Faculty of Education at Christ Church. Simon's PhD is from Birmingham University and his MEd is from Leicester University.

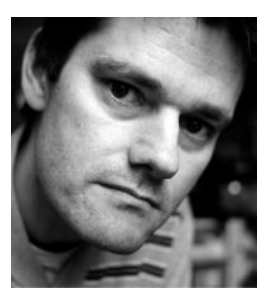

Kris Roger

Kris Roger is a Senior Learning Technologist within the Learning Technology and Innovation team at LSE. Kris has a wide range of interests and expertise within the learning technology field including educational use of digital media; lecture recording; use of mobile devices for learning; effective VLE use and the design of learning spaces and technology used within.

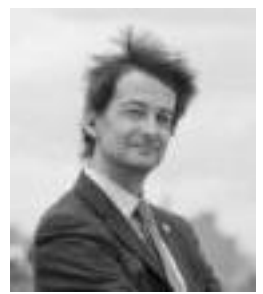

\section{Sebastiaan Eldritch-Böersen}

Sebastiaan Eldritch-Böersen is a graduate of the University of Leeds and postgraduate student at the University of Bath. His academic background originated in Sociology and Social Policy. After completing graduate studies, Sebastiaan invested time working in various Disability Rights and Disability Support environments, and this is where he found his passion. Sebastiaan subscribes to the 'nothing about us without us' model of consultation regarding support networks and anticipatory models of thinking.

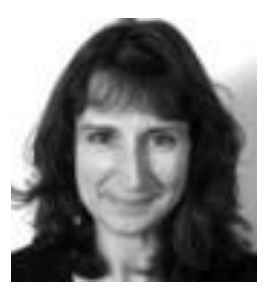

\section{Linda Kelland}

Linda Kelland is a Neurodiversity Service Manager at the LSE. She has had a varied career path and, before training as a dyslexia tutor, she worked as an Electrical Design Engineer. Linda started working at the LSE as a dyslexia advisor in $\mathbf{2 0 0 4}$ and she so enjoyed working with students that she is now the Neurodiversity Services Manager. She works with the Neurodiversity Service, which reflects the service's philosophy of valuing 'equal but different thinking.' 